\title{
Frequência de ovinos soropositivos para lentivírus de pequenos ruminantes no município de Colinas do Tocantins, estado do Tocantins, Brasil
}

\author{
Frequency of antibodies against ovine Lentivirus \\ in sheep in Colinas do Tocantins, Tocantins state, Brazil

\begin{abstract}
Cristiane Lopes Mazzinghy ${ }^{1 *}$, Katyane de Sousa Almeida ${ }^{1}$, Josir Laine Aparecida Veschi², Roberto Soares de Castro ${ }^{3}$, Nekita Évely Ximenes Martinss ${ }^{4}$, Marlos Gonçalves Sousa ${ }^{1}$
\end{abstract}

| | | | | | | | | | | | | | | | | | | | | | | | | | | | | | | | | | | | | | | | | | | | | | | | | | | | | | | | | | | | | | | | | | | | | | | | | | | | | | | | | | | | | | | | | | | | | | | | | | | | | | | | | | | | | | | | | | | | | | | | | | | | | | | | | | | | | | | | | | | | | | | | | | | | | | | | | | | | | | | | | | | | | | | | | | | | | | | | | | | | | | | | | | | | | | | | | | | | | | |

RESUMO: Maedi-Visna (MV) é uma enfermidade causada por lentivírus de pequenos ruminantes com evoluçáo crônica e em grande parte dos casos sinais clínicos inaparentes. O diagnóstico da doença é baseado em sinais clínicos e dados epidemiológicos, sendo a imunodifusão em gel de ágar (IDGA) o método padrão para a detecção sorológica de anticorpos contra o lentivírus. Sabendo que o estado do Tocantins possui potencial para o desenvolvimento da ovinocultura e que grande parte dos produtores de Colinas do Tocantins, no referido estado, possui interesse em estabelecer criação racional, esta pesquisa teve por objetivo a realizaçáo de um estudo acerca da soroprevalência da doença. Foram coletadas 369 amostras de sangue de ovinos, independentemente de raça, sexo e idade, de diferentes propriedades rurais do município para diagnóstico de MV utilizando a técnica de IDGA. Após as análises laboratoriais, para avaliação dos resultados no tocante às categorias, foi utilizado o teste exato de Fisher e também foi calculado o odds ratio, com intervalo de confiança de $95 \%$ para verificação da idade como possível fator de risco ou de proteção. Constatou-se que 6 animais $(1,62 \%)$ se apresentaram positivos no IDGA. Diante desses resultados, foi possível concluir que a frequência de ovinos soropositivos no município é baixa.

PALAVRAS-CHAVE: inquérito epidemiológico; Maedi-Visna; sorologia.

\begin{abstract}
Maedi-Visna is a disease caused by a small ruminant lentivirus, with a chronic evolution and, in most cases, unapparent signs. Its diagnosis is based on clinical signs and epidemiological data, with the agar gel immunodiffusion (AGID) test being the classical method for detecting antibodies against lentiviruses. Considering that the state of Tocantins has the potential to develop sheep breeding and that the majority of producers from Colinas do Tocantins city has shown an interest in establishing a rational breeding, this study aimed to determine the prevalence of such disease in that region. A total of 369 blood samples was drawn from sheep bred in several farms of that town, regardless of breed, gender, and age. Every sample underwent an AGID to test for Maedi-Visna. After the laboratory analyses were concluded, the Fisher's exact test was used to evaluate the results against the categories. Also, the odds ratio, with $95 \%$ confidence interval, was calculated to check whether age played a role as either a risk or protective factor in these results. It was found that six animals (1.62\%) were positive in AGID, therefore concluding that the frequency of seropositivity in that region is low.
\end{abstract}

KEYWORDS: epidemiological investigation; Maedi-Visna; serology.

\footnotetext{
'Laboratório de Higiene e Saúde Pública; Universidade Federal do Tocantins (UFT) - Araguaína (TO), Brasil.

${ }^{2}$ Sanidade Animal; Empresa Brasileira de Pesquisa Agropecuária (Embrapa) Semiárido - Petrolina (PE), Brasil.

${ }^{3}$ Departamento de Medicina Veterinária; Universidade Federal Rural do Pernambuco (UFRPE) - Recife (PE), Brasil.

${ }^{4}$ Programa de Pós-Graduação em Ciência Animal Tropical; UFT - Araguaína (TO), Brasil.

*Autor correspondente: crislp03@yahoo.com.br

Recebido em: 30/05/2014. Aceito em: 05/04/2016
} 


\section{INTRODUÇÃO}

Maedi-Visna é infecção multissistêmica causada pelo lentivírus e possui evolução geralmente crônica e muitas vezes com sinais inaparentes. As principais manifestaçôes clínicas da doença, quando presentes, são quadros de dispneia, emagrecimento, encefalite, mamite, artrite e linfadenopatia (SHEFFIELD et al., 1980; Mota, 2008, Ramírez et al., 2012).

A enfermidade encontra-se difundida nos rebanhos ovinos do Brasil e, apesar de a prevalência da doença manter-se baixa, há a presença do vírus em grande parte das regióes investigadas (Costa et al., 2007; Souza et al., 2007), sendo evidenciada prevalência de 0,3 e 0,5\% em municípios da Bahia (Souza et al., 2007; Martinez et al., 2011), 0,5 e 4,9\% no Ceará (Araújo et al., 2004), ocorrência de 1 a 8,2\% em regióes distintas de Pernambuco (Costa et al., 2007; Oliveira et al., 2006), 2,8\% no Rio Grande do Sul (Fernandes et al., 2011), 2,7\% em São Paulo (Lombardi et al., 2009), 0,6\% em Sergipe (D'ALENCAR et al., 2008) e prevalência de 0,9\% no Tocantins (Moura Sobrinho et al., 2008).

Existem ainda algumas regióes dos estados em que inquéritos sorológicos acerca do vírus Maedi-Visna (MVV) obtiveram ocorrências nulas, como em regióes do Piauí (SiLVA, 2011), de Sergipe (Melo et al., 2003), de Manaus (Lima, 2011), de São Paulo (Gregory et al., 2013), do Mato Grosso (Manhezzo et al., 2011) e de Minas Gerais (Yorinori, 2001; SAlaberry et al., 2010). No Ceará, houve a variação de ocorrência nula a 50,43\% em regióes distintas (Almeida et al., 2002), da mesma forma em Minas Gerais, com prevalência de 7,9\% ao analisar nove mesorregióes do estado (Marques, 2006).

Com isso, observa-se a necessidade da realização de levantamentos mais amplos para investigar a prevalência da enfermidade nos estados. Diante do interesse de produtores de ovinos da cidade de Colinas do Tocantins (TO) em estabelecer uma criação racional, desenvolveu-se o presente estudo, a fim de verificar a soroprevalência de MVV nos rebanhos de ovinos no município.

A coleta de amostras aconteceu entre os meses de março e maio de 2011, em propriedades criadoras de ovinos de Colinas do Tocantins. O município encontra-se a $277 \mathrm{~m}$ de altitude em relação ao nível do mar, com latitude de $8.05532^{\circ}$ S e longitude de $48.477345^{\circ} \mathrm{W}$. O clima da região é tropical úmido com temperatura média de aproximadamente $26^{\circ} \mathrm{C}$, sendo os meses mais chuvosos dezembro, janeiro e fevereiro (Prefeitura de Colinas do Tocantins, 2011). A cidade possui um sindicato rural para ovinocultores, no qual são cadastradas todas as propriedades criadoras de ovino do município, totalizando 16 fazendas. Destas, 13 foram visitadas durante este estudo. A microrregiáo de Colinas do Tocantins apresenta cerca de 1\% de todo o efetivo de ovinos do estado do Tocantins (BrasIL, 2016) com animais sem raça definida oriundos do Nordeste brasileiro e criados em sistema extensivo juntamente com outras culturas.
Para o cálculo da amostra, utilizou-se o Programa Integrado para uso em Epidemiologia (Epi Info 6.04) (DeAn et al., 1996). Considerou-se a possibilidade de detecção da doença em 50\%, intervalo de confiança de 95\% (IC95\%) e erro estatístico de $5 \%$, resultando no número amostral de 369 animais.

O rebanho experimental foi constituído por animais sem raça definida tendo em vista duas categorias produtivas: animais jovens e em reprodução. Foram examinados 20\% do total de animais de cada categoria em cada propriedade, exceção feita aos machos reprodutores, que foram examinados em sua totalidade. Das 369 amostras analisadas, 43 eram fêmeas jovens, 180 fêmeas adultas, 71 machos jovens e 75 machos adultos. A investigação foi desenvolvida seguindo as normas do Comitê de Ética da Universidade Federal do Tocantins (UFT), aprovada sob o n. ${ }^{\circ}$ 23101.003941/2012-12. O teste sorológico utilizado foi a imunodifusão em gel de ágar (IDGA), por intermédio de kits produzidos e comercializados pela Biovetech $^{\circledR}$, e a técnica realizada de acordo com instruçôes do fabricante.

Para o cálculo da frequência da enfermidade no rebanho, foi empregada análise estatística descritiva, por meio de distribuição absoluta e relativa. Para avaliação dos resultados no que se refere às categorias idade (animais jovens ou em reprodução) e sexo (macho e fêmea), foi usado o teste exato de Fisher, sendo ainda calculado a odds ratio, com IC95\% para verificação de idade e sexo como possíveis fatores de risco ou proteção. As análises estatísticas foram feitas no programa estatístico GraphPad Prism ${ }^{\circledR}$ versão 5.04, adotando-se o nível de significância de 5\%.

Das 369 amostras de soros de ovinos averiguadas pelo teste de IDGA, 1,62\% (6/369) foram positivas para Maedi-Visna com a formação de linha de identidade, confirmando a presença de anticorpos contra o vírus em animais no município de Colinas do Tocantins. Das 13 propriedades que tiveram animais examinados, três apresentaram animais sorologicamente positivos, todavia esses animais não demonstravam sinais clínicos da doença.

Com relação à idade, apesar de se observar superioridade na frequência de animais adultos com resultados positivos, não houve associação entre idade e soroprevalência (Tabela 1). A análise da relação entre sexo e soroprevalência de MVV não revelou nenhuma associação entre ambos (Tabela 2).

Moura Sobrinho et al. (2008), examinando a frequência do vírus em cinco municípios do Tocantins, constataram oito focos da doença, sendo três em Alvorada, dois em Araguatins e um em Babaçulândia, em Pequizeiro e em Guaraí. Os autores verificaram soropositividade de $0,9 \%$ no estado e associaram a baixa prevalência na região-alvo de estudo à recente formação do rebanho no estado e às exigências de animais com sorologia negativa para lentivírus por parte dos produtores ao adquiri-los. Portanto, mesmo diante da baixa taxa de soropositividade para MVV na região de Colinas do Tocantins, essa taxa já está acima do esperado. 
Tabela 1. Análise da influência do critério idade na soroprevalência para lentivírus de pequenos ruminantes em ovinos pelo teste de imunodifusão de gel de ágar (IDAG), no município de Colinas do Tocantins, TO, 2012.

\begin{tabular}{|c|c|c|c|c|c|c|}
\hline Idade & Reagentes & $\%$ & Total & $\%$ & Valor p & OR (IC95\%) \\
\hline Jovens & 0 & 0 & 115 & 31,16 & \multirow{3}{*}{$0,1828^{*}$} & \multirow{3}{*}{$\begin{array}{c}6,042 \\
(0,33-1,08)\end{array}$} \\
\hline Reprodução & 6 & 2,36 & 254 & 68,83 & & \\
\hline Total & 6 & 1,62 & 369 & 100 & & \\
\hline
\end{tabular}

OR: odds ratio; IC95\%: intervalo de confiança de 95\%; *teste exato de Fisher a 5\% de significância.

Tabela 2. Análise da influência do critério sexo na soroprevalência para lentivírus de pequenos ruminantes em ovinos pelo teste de imunodifusão de gel de ágar (IDAG), no município de Colinas do Tocantins, TO, 2012.

\begin{tabular}{|c|c|c|c|c|c|c|}
\hline Sexo & Reagentes & $\%$ & Total & $\%$ & Valor $\mathrm{p}$ & OR (IC95\%) \\
\hline Fêmeas & 3 & 1,32 & 223 & 60,43 & \multirow{3}{*}{$0,6807^{*}$} & \multirow{3}{*}{$\begin{array}{c}1,593 \\
(0,31-8,0)\end{array}$} \\
\hline Machos & 3 & 2,05 & 146 & 39,57 & & \\
\hline Total & 6 & 1,62 & 369 & 100 & & \\
\hline
\end{tabular}

OR: odds ratio; IC95\%: intervalo de confiança de 95\%; *teste exato de Fisher a 5\% de significância.

A obtenção de resultados soronegativos é uma medida preventiva eficiente contra a introdução de novos casos no estado do Tocantins, uma vez que regióes em fase de aumento do seu efetivo acabam adquirindo grande quantidade de animais, ficando sujeitas ao risco maior de adquirir animais com problemas sanitários (MARQues, 2006). Assim, a investigação acerca da doença pode identificar esses focos e disponibilizar dados para a elaboração de um programa de controle eficaz, evitando a disseminação para os plantéis do estado.

No que diz respeito à relação entre a ocorrência da MVV e o sexo, bem como a associaçáo entre a soroprevalência e a idade, não se evidenciou nenhuma diferença significativa. Estudos anteriores já reportaram a ausência de relação entre as duas variáveis e a soropositividade (Oliveira et al., 2006; MARTinez et al., 2011).

O sistema de criação dos animais nos rebanhos já foi relatado influenciando o desenvolvimento da MVV, com tendência de aumento da prevalência da enfermidade em criaçóes intensivas (MarTINEZ et al., 2010). Nas propriedades da microrregião de Colinas do Tocantins o sistema de criação predominante é o extensivo, e a baixa frequência da enfermidade na regiáo pode estar associada ao tipo de criação, em que os animais não permanecem aglomerados, dificultando a transmissão. Em contrapartida, apesar do menor risco de transmissão via aerossóis, os animais tornam-se suscetíveis à ação do lentivírus pelo livre acesso a restos de partos e secreçôes urogenitais contaminadas.

Segundo os criadores de ovinos da microrregião de Colinas do Tocantins, o rebanho é oriundo da região Nordeste do Brasil, principalmente da Bahia e do Ceará. Almeida et al. (2002) detectaram prevalência de 31,67\% em ovinos em diferentes regióes do Ceará, verificando a existência do lentivírus ovino no rebanho e a disseminação pelo estado, podendo atingir estados vizinhos.

A enfermidade remete a restriçóes de exportaçáo, desvalorização do rebanho e redução da produção decorrente da doença, impossibilitando o desenvolvimento da atividade na região. O diagnóstico sorológico e o sacrifício de animais soropositivos não acarretariam grandes prejuízos ao produtor, em função da baixa frequência da enfermidade na microrregião de Colinas do Tocantins, de forma que essa medida, associada à realização da sorologia antes de introduzir novos animais no estado, seria importante para a economia e para a produçáo local, pois atuaria não apenas no controle como na erradicação da doença no município.
ALMEIDA, N.C.; APRIGIO, C.J.L; SILVA, J.B.A.; TEIXEIRA, M.F.S. Ocorrência de maedi/visna vírus em ovinos reprodutores no estado do Ceará. In: CONGRESSO BRASILEIRO DE MEDICINA VETERINÁRIA, 29., 2002, Gramado. Anais... Gramado: SOVERGS, 2002. Disponível em: <http://www.sovergs.com.br/site/ conbravet2002/1517.htm>. Acesso em: 12 out. 2016.
ARAÚJO, S.A.C.; DANTAS, T.V.M.; SILVA, J.B.A.; RIBEIRO, A.L.; RICARTE, A.R.F.; TEIXEIRA, M.F.S. Identificação do Maedi-Visna vírus em pulmão de ovinos infectados naturalmente. Arquivos do Instituto Biológico, São Paulo, v.71, n.4, p.431-436, 2004. 
BRASIL. Instituto Brasileiro de Geografia e Estatística (IBGE). Cidades. 2016. Disponível em: <http://cidades. ibge.gov.br/xtras/perfil.php?codmun $=170550>$. Acesso em: 7 set. 2016 .

COSTA, L.S.P.; LIMA, P.P.; CALLADO, A.K.C.; NASCIMENTO, S.A.; CASTRO, R.S. Lentivírus de pequenos ruminantes em ovinos Santa Inês: isolamento, identificação pela PCR e inquérito sorológico no estado de Pernambuco. Arquivos do Instituto Biológico, São Paulo, v.74, n.1, p. $11-16,2007$.

D'ALENCAR, C.E.; BARROS, S.L.B.; D'ALENCAR MENDONÇA, M.A.; FRANCO, I.; LISBO, M.L.O.; PINHEIRO, R.R. Detecção de ovino sororreagente para Maedi-Visna no estado de Sergipe. In: CONGRESSO BRASILEIRO DE MEDICINA VETERINÁRIA, 35., 2008, Porto Alegre. Anais... Porto Alegre: SOVERGS, 2008. Disponível em: <https://www.embrapa.br/busca-de-publicacoes/-/publicacao/528847/deteccao-de-ovino-sororreag ente-para-maedi-visna-no-estado-de-sergipe >. Acesso em: 21 jan. 2013.

DEAN, G.A.; DEAN, A.J.; COULOMBIER, D.; BRENDEL, K.A.; SMITH, D.C.; BURTON, A.H.; DICKER, R.C.; SULIVAN, K.M.; FAGAN, R.F.; ARNER, T.G. Epi Info, version 6: a word-processing, database, and statistic program for epidemiology on microcomputers. Atlanta: Center for Diseases Control and Prevention, 1996.

FERNANDES, L.G.; FREITAS, F.J.C.; LIMA, J.M.; SAKAMOTO, S.M. Ocorrência de caprinos e ovinos soropositivos para lentivírus provenientes de exposições agropecuárias do Rio Grande do Norte. In: CONGRESSO BRASILEIRO DE MEDICINA VETERINÁRIA, 38., 201 1, Florianópolis. Anais... Florianópolis: SOVERGS, 2011 . Disponível em: <http://www.sovergs.com. $\mathrm{br} / \mathrm{site} / 38$ conbravet/resumos/1004.pdf >. Acesso em: 21 jan. 2013.

GREGORY, L.; LARA, M.C.C.S.H.; KIRALY, A.C.M.; HASEGAWA, M.Y.; RIZZO, H.; HENRIQUES, L.C.S.; CASTRO, R.S. Pesquisa de anticorpos contra Maedi-Visna em ovinos nas microrregiões de Botucatu, Campinas, Piedade e São Paulo, estado de São Paulo. Arquivos do Instituto Biológico, São Paulo, v.80, n.1, p. $107-110,2013$.

LIMA, N.S. Incidência de Maedi-Visna na população de ovinos (Ovis aries) em propriedades rurais da região metropolitana de Manaus - AM. 2011 . 35f. Dissertação (Mestrado em Medicina Veterinária) - Escola Superior Batista do Amazonas, Manaus, 2011.

LOMBARDI, A.L.; NOGUEIRA, A.H.C.; FERES, F.C.; PAULO, H.P.; CASTRO, R.S.; FEITOSA, F.L.F; CADIOLI, F.A.; PEIRÓ, J.R.; PERRI, S.H.V.; LIMA, V.F.M.; MENDES, L.C.N. Soroprevalência de Maedi-Visna em ovinos na região de Araçatuba, SP. Arquivo Brasileiro de Medicina Veterinária e Zootecnia, Belo Horizonte, v.61, n.6, p.1.434-1.437, 2009. DOI: 10.1590/ SO $102-09352009000600025$

MANHEZZO, T.G.; HEIDMANN, M.J.; VALLE, R.V.; AZEVEDO, D.A.A.; CASTRO, B.G.; PINHEIRO, R.R. Prevalência de Maedi-Visna em ovinos de Sinop e região, Mato Grosso, Brasil. In: SIMPÓSIO INTERNACIONAL SOBRE CAPRINOS E OVINOS DE CORTE, 5., 2011 , João Pessoa. Anais... João Pessoa, 2011 . Disponível em: <http://www.alice.cnptia.embrapa.br/handle/doc/905799>. Acesso em: 18 jan. 2013.
MARQUES, A.P.R. Caracterização soroepidemiológica da infecção por vírus Maedi-Visna e Brucella ovis em ovinos no estado de Minas Gerais. 2006. 79p. Dissertação (Mestrado em Medicina Veterinária) Universidade Federal de Minas Gerais, Belo Horizonte, 2006. Disponível em: <http://www.bibliotecadigital.ufmg.br/dspace/ handle/1843/SSLA-7VGHRK>. Acesso em: 18 jan. 2013.

MARTINEZ, P.M.; COSTA, J.N.; SOUZA, T.S.; COSTA NETO, A.O.; PINHEIRO, R.R. Sistema de criação de ovinos e ocorrência de anticorpos contra o vírus da Maedi-Visna na microrregião de Juazeiro, BA. Revista Brasileira de Saúde e Produção, Salvador, v.11, n.2, p.342-353, 2010.

MARTINEZ, P.M.; COSTA, J.N.; SOUZA, T.S.; LIMA, C.C.V.; COSTA NETO, A.O.; PINHEIRO, R.R. Prevalência sorológica da Maedi-Visna em rebanhos ovinos da microrregião de Juazeiro. Ciência Animal Brasileira, Goiânia, v.12, n.2, p.322-329, 2011.

MELO, C.B.; CASTRO, R.S.; OLIVEIRA, A.A.; FONTES, L.B.; CALLADO, A.K.C.; NASCIMENTO, S.A. Estudo preliminar sobre a infecção por lentivírus de pequenos ruminantes em ovinos e caprinos em Sergipe. In: CONGRESSO BRASILEIRO DE BUIATRIA, 5., 2003, Salvador. Anais... Salvador: Associação Brasileira de Buiatria, 2003. Disponível em: <http://www.bdpa.cnptia.embrapa.br/bus $\mathrm{ca}$ ?b=ad\&id=529799\&biblioteca=vazio\&busca=autoria:\%22F ONTES,\%2OL.\%2OB.\%22\&qFacets=autoria:\%22FONTES,\%20 L. $\% 20 B . \% 22 \&$ sort $=\&$ paginacao $=$ t\&paginaAtual $=1>$. Acesso em: 18 jan. 2013.

MOTA, R.A. Aspectos epidemiológicos, diagnóstico e controle das mastites em caprinos e ovinos. Tecnologia @ Ciência Agropecuária, João Pessoa, v.2, n.3, p.57-61, 2008.

MOURA SOBRINHO, P.A.; FERNANDES, C.H.C; RAMOS, T.R.R; CAMPOS, A.C.; COSTA, L.M.; CASTRO, R.S. Prevalência e fatores associados à infecção por lentivírus de pequenos ruminantes em ovinos no Estado do Tocantins. Ciência Veterinária dos Trópicos, Recife, v. 11 , n.2-3, p.65-72, 2008.

OLIVEIRA, M.M.M.; CASTRO, R.S.; CARNEIRO, K.L; NASCIMENTO, S.A.; CALLADO, A.K.C.; ALENCAR, C.S.A.; COSTA, L.S.P. Anticorpos contra lentivírus de pequenos ruminantes em caprinos e ovinos em abatedouros do estado de Pernambuco. Arquivo Brasileiro de Medicina Veterinária e Zootecnia, Belo Horizonte, v.58, n.5, p.947-949, 2006. DOI: 10.1590/ so102-09352006000500035

PREFEITURA DE COLINAS DO TOCANTINS. A cidade. 2011. Disponível em: <http://colinas.to.gov.br/a-cidade/>. Acesso em: 25 jun. 2012.

RAMÍREZ, H.; REINA, R.; BERTOLOTTI, L.; CENOZ, A.; HERNÁNDEZ, M.; ROMÁN, B.S.; GLARIA, I.; ANDRÉS, X.; CRESPO, H.; JÁUREGUI, P.; BENAVIDES, J.; POLLEDO, L.; PÉREZ, V.; GARCÍA-MARÍN, J.; ROSATI, S.; AMORENA, B.; ANDRÉS, A. Study of compartmentalization in the visna clinical form of small ruminant lentivirus infection in sheep. BMC Veterinary Research, Londres, v.8, n.8, p. $112,2012$. DOI: $10.1186 / 1746-6148-8-8$

SALABERRY, S.R.S.; LARA, M.C.C.S.H.; PIATTI, R.M.; NASSAR, A.F.C.; CASTRO, J.R.; GUIMARÃES, E.C.; LIMA-RIBEIRO, A.M.C. Prevalência de anticorpos contra os agentes da Maedi-Visna e clamidofilose em ovinos no município de Uberlândia, MG. Arquivos do Instituto Biológico, São Paulo, v.77, n.3, p.411-417, 2010. 
SHEFFIELD, W.D.; NARAYANJ, D.; STRANDBERG, J.D.; ADAMS, J. Visna-Maedi-like disease associated with an ovine retrovirus infection in a corriedale sheep. Veterinary Pathology, Thousand Oaks, v.17, n.5, p.544-552, 1980. DOI: $10.1177 / 030098588001700503$

SILVA, R.A.B. Caracterização epidemiológica das lentiviroses de pequenos ruminantes na microrregião homogênea de Teresina, Piauí. 201 1. 99p. Dissertação (Mestrado em Ciência Animal) Universidade Federal do Piauí, Teresina, 2011. Disponível em <http://leg.ufpi.br/subsiteFiles/ciencianimal/arquivos/files/ Dissert.pdf> Acesso em: 5 fev. 2013.
SOUZA, T.S.; COSTA, J.N.; MARTINEZ, P.M.; PINHEIRO, R.R. Estudo sorológico da Maedi-Visna pelo método de imunodifusão em gel de ágar em rebanhos ovinos de Juazeiro, Bahia, Brasil. Revista Brasileira de Saúde e Produção Animal, Salvador, v.8, n.4, p.276-282, 2007.

YORINORI, E.H. Características dos sistemas de produção de pequenos ruminantes e prevalências da artrite-encefalite caprina (CAE) e Maedi-Visna (MV) ovina, nas regiões norte e nordeste de Minas Gerais. 2001. 113p. Dissertação (Mestrado em Medicina Veterinária) - Universidade Federal de Minas Gerais, Belo Horizonte, 2001. Disponível em: <http://www.bibliotecadigital.ufmg.br/ dspace/handle/1843/BUDB-8BSHJ7>. Acesso em: 5 fev. 2013. 